\title{
Localized Gastric Carcinoma
}

National Cancer Institute

\section{Source}

National Cancer Institute. Localized Gastric Carcinoma. NCI Thesaurus. Code C156167.

A carcinoma that arises from the stomach and has not spread to other anatomic sites. 